\title{
Portuguese version of the Tilburg Frailty Indicator: Transcultural adaptation and psychometric validation
}

\author{
Tiago Coelho, Rubim Santos, Constança Paúl, Robbert JJ Gobbens and Lia Fernandes
}

\begin{abstract}
Aim: To present the translation and validation process of the Portuguese version of the Tilburg Frailty Indicator (TFI).

Methods: A cross-sectional study was designed using a non-probability sample of 252 community-dwelling older adults. Preliminary studies were carried out for face and content validity assessment. Internal consistency, test-retest reliability, construct (convergent/divergent) and criterion validity were subsequently analyzed.
\end{abstract}

Results: The sample was mainly women $(75.8 \%)$, with a mean age of $79.2 \pm 7.3$ years. TFI internal consistency was good $($ KR-20 $=0.78)$. Test-retest reliability for the total was also good $(r=0.91)$, with kappa coefficients showing substantial agreement for most items. TFI physical and social domains correlated as expected with concurrent measures, whereas the TFI psychological domain showed similar correlations with other psychological and physical measures. The TFI showed a good to excellent discrimination ability in regard to frailty criteria, and fair to good ability to predict adverse outcomes.

Conclusions: The psychometric properties of the TFI seem to be consistently good. These findings provide initial evidence that the Portuguese version is a valid and reliable measure for assessing frailty in the elderly.

Keywords: elderly, frailty, Tilburg Frailty Indicator, validation study.

\section{Introduction}

Portugal is no exception to the worldwide trend of population aging, with one of the highest proportions $(19 \%)$ of elderly in the European Union. ${ }^{1}$ As life expectancy increases, so does the need to maintain health and independence during a longer life. Despite the heterogeneity of functional decline with chronological age, frailty is considered to be highly prevalent in elderly individuals. ${ }^{2,3}$

Over the past three decades, the relevance of the concept of frailty has increased significantly in the study of aging and the clinical care of older adults. ${ }^{4-6}$ Frailty is generally recognized as a state of increased vulnerability that entails a high risk of clinically significant adverse outcomes, such as falls, disability, hospitalization, institutionalization and mortality. ${ }^{7-9}$ However, there is no agreed definition., ${ }^{2,10,11}$ Although frailty is commonly accepted as a clinically observable syndrome that results from a significantly diminished physiological reserve and its interplay with life course determinants and/or disease(s), which affect the individual's ability to maintain homeostasis when facing stressors, the same cannot be said about its outcomes and, especially, its components. ${ }^{12-14}$ A recent literature review shows that despite some factors, there has been a greater number in differing approaches regarding the components and the adverse outcomes of frailty (e.g. physical function and death), over which there is still a lot of controversy. ${ }^{15}$ Nevertheless, two major trends in the conceptualization of frailty have been identified. An increasing number of authors state that disability is an outcome of frailty rather than a component of the syndrome. Disability, 
such as morbidity and the normal process of aging, is not synonymous with frailty. ${ }^{4,5,16,17}$ Progressively more studies emphasize the need for including psychosocial factors in the definition of frailty, instead of conceptualizing it as consisting of exclusively physical conditions. ${ }^{6,7,15,18}$

Traditional approaches of frailty emphasize physical losses that result from functional decline across multiple physiological systems (e.g. musculoskeletal, immune, hormonal, inflammatory, autonomic/central nervous system) and its physical manifestations (e.g. sarcopenia). ${ }^{13,19-21}$ From these approaches, a consensus has been reached on the operationalization of frailty that is known as the frailty phenotype, in which the clinical presentation of the syndrome refers to the presence of three or more of the following components: unintentional weight loss, low physical activity, exhaustion, slow walking speed and weakness. ${ }^{3}$ However, there is an increasing number of researchers with a more integrative, multidimensional and health-based perspective, avoiding the fragmentation of care for older adults. ${ }^{2,6,22-}$ ${ }^{27}$ In order to make sense of a multidimen- sional approach to frailty and, at the same time, to clearly differentiate frailty from disability, an integral conceptual model has been developed, resulting from an exhaustive literature review and expert consultation. ${ }^{5,18,26,28}$ The need to identify frailty according to this conceptualization has led to the development of the Tilburg Frailty Indicator (TFI). ${ }^{29}$

Considering that most researchers agree that frailty and its adverse outcomes can be prevented, the ability to effectively assess frailty should be of great relevance, from a social and public health perspective. ${ }^{2}$ In this context, TFI allows the screening of frailty in community-dwelling older people, according to the more recent approaches. ${ }^{29}$ Taking into account that there is no Portuguese version of TFI, the present study aimed to translate and validate this instrument.

\section{Methods}

\section{Sample}

From May to September 2013, a non-probability sample of 252 elderly volunteers from three northern Portuguese cities (Maia, Porto, Vila Nova de Gaia) was recruited. These persons, users of institutions, such as social, recreation and day care centers, and senior academies, were interviewed. The inclusion criteria was community dwellers aged $\geq 65$ years. Individuals with severe cognitive impairment or unable to speak Portuguese were excluded. Data collection was carried out by nine trained researchers. For test-retest reliability, the first 74 available participants were assessed twice with TFI within a 12-16-day period (mean 14 days). The study was approved by institutional review boards, and all participants gave their written informed consent.

\section{Description of TFI}

TFI is a brief self-report questionnaire for screening frail community-dwelling older adults with two subscales: part A-10 items about determinants of frailty (e.g. age, sex, education and income); and part B-15 questions divided into three domains (physical, psychological and social), and focuses exclusively on components of frailty. The part B set of items inform frailty total and each domain score as follows. A total of 11 items have two response categories (yes/no), while four items have three (yes/no/sometimes). Nevertheless, all items are scored zero or one. The TFI physical domain includes eight questions about physical health, unexplained weight loss, difficulty in walking, difficulty in maintaining balance, hearing problems, vision problems, lack of strength in hands and physical tiredness. The psychological domain comprises four items related to cognition, depressive/anxiety symptoms and coping mechanisms. The social domain includes three items: living alone, social relations and social support. The originally proposed cut-off for frailty was $5 .^{29}$

For screening purposes, TFI can be administered alone, without supplementary assessment tools. This possibility is supported by the observed association of TFI domains with concurrent measures. ${ }^{29}$ Furthermore, previous studies have shown that TFI is sufficient to predict healthcare utilization, 1 and 2 years later. ${ }^{30} \mathrm{Nev}$ ertheless, to better predict disability, the use of both TFI and the Timed Up and Go test (TUG) $)^{31}$ is recommended. ${ }^{30}$ Also, a previous screening of severe cognitive deficit might be advised, because of the self-reporting nature of TFI.

TFI was recently developed with tested psychometric properties in the Netherlands. ${ }^{29}$ An English version was promptly made available by the authors, resulting from a translation and back-translation process. Since then, a valid and cross-culturally adapted version was prepared in Brazil ${ }^{32,33}$ and Denmark. ${ }^{34}$ Furthermore, studies carried out by different researchers ${ }^{35,36}$ highlighted TFI psychometric properties in comparison with other frailty measures.

\section{Translation and cultural adaptation process}

This process was carried out according to the guidelines of the International Society for Pharmacoeconomics and Outcomes Research, beginning with permission to use the TFI and inviting the main author of the questionnaire to be involved in the research. ${ }^{37}$ Forward translation from English into Portuguese was carried out by three authors of this research, who are fluent in English. After the forward translations had been 
analyzed, and a single forward translation agreed on, the back translation was carried out by two professional English translators. The back translation results were reviewed, and a harmonization of all versions was sought to detect and deal with any discrepancies that could have arisen between different language versions, ensuring conceptual equivalence. To assess the level of comprehensibility of the translation, a cognitive debriefing was carried out, involving a pretest with six participants that would be eligible for this research. Additionally, a multidisciplinary committee (five experts regarding geriatric research) was consulted to provide their opinion on the face and content validity of the preliminary version. Pretest results along with multidisciplinary group feedback suggested good face and content validity. The final version was proofread and then used for psychometric testing.

\section{Additional measures}

To examine the construct validity of TFI, the following measures of physical, psychological and social frailty components were used: body mass index (BMI), $\mathrm{TUG}^{31}$ handgrip strength, center of pressure (COP) sway analysis, Mini-Mental State Examination (MMSE), ${ }^{38,39}$ Geriatric Depression Scale (GDS), ${ }^{40}$ Geriatric Anxiety Inventory $(\mathrm{GAI})^{41,42}$ and Social Support Satisfaction Scale (SSSS). ${ }^{43}$

To study the criterion validity, frailty was also identified through alternative frailty specific measures: the Groningen Frailty Indicator (GFI) and an operationalization of the frailty phenotype..$^{44,45}$ Adverse outcomes (disability and healthcare utilization) and quality of life were equally assessed for the same purpose. Disability in basic activities of daily living (ADL) was measured with the Barthel Index ${ }^{46,47}$ and in instrumental ADL with the Lawton and Brody Scale. ${ }^{48,49}$ Quality of life was assessed with EUROHIS Quality of Life 8-item index (EUROHIS-QOL-8), ${ }^{50,51}$ and World Health Organization Quality of Life - Old Module (WHOQOL-OLD). ${ }^{52,53}$

Hand strength was measured with a GRIP-D Takei Hand Grip Dynamometer (T.K.K. 5401; Takei Scientific Instruments, Tokyo, Japan) and considering a proposed standardized approach. ${ }^{54} \mathrm{COP}$ sway, which is usually measured to assess postural control and balance, was analyzed with an Emed-AT25D pressure platform (Novel, Munich, Germany). ${ }^{55}$ The parameters measured were maximum velocity and maximum range in medial/lateral/COP $\mathrm{X}$ and anterior/posterior/COP axis, during two tasks carried out while standing (eyes open/eyes closed). In regard to frailty phenotype components: unintentional weight loss was considered if answered "yes" to TFI question 12, "Have you lost a lot of weight recently without wishing to do so?". Low physical activity and exhaustion were detected using two questions based on previous studies. ${ }^{56}$ Slow walking speed was detected if the participant took more than $20 \mathrm{~s}$ to complete the TUG. Weakness was identified if the participant's hand strength was below the cut-off determined by Fried et al. stratified by sex and BMI. ${ }^{3}$ Frailty was identified if the participant had $\geq 3$ components, and prefrailty if one or two components were present. Healthcare utilization was assessed with a set of questions previously used in other studies and referred only to the last year. $28,29,57$

See Supporting Information for more details about the additional measures used.

\section{Statistical analysis}

Internal consistency was assessed using the KuderRichardson formula (KR-20), which is equivalent to Cronbach's alpha, but used for dichotomous measures. Test-retest reliability was measured by calculating the Pearson correlation coefficient for each domain and for total score, and by assessing simple agreement and Cohen's kappa coefficient for each TFI item.

Construct validity was determined by the Spearman correlations between TFI domains score and other measures. It was expected that each score would show higher correlations with measures of the same domain of human functioning, and lower correlations with measurements of other domains (convergent/divergent validity).

Criterion validity was primarily assessed by carrying out receiver operating characteristic (ROC) analysis applied to the criteria of frailty and adverse outcomes: disability and healthcare utilization. Criterion validity was also assessed by multiple regression analysis in order to ascertain if TFI multiple domains predict quality of life, as evidenced in other studies. ${ }^{29,57,58}$ The association of quality of life with frailty domains, after controlling for the effect of the other domains, was also analyzed.

Two-tailed tests were used, and a $P<0.05$ was considered statistically significant. For statistical analysis, IBM SPSS Statistics 22.0 (IBM, Armonk, NY, USA) was used.

\section{Results}

\section{Sample}

The sample comprised 252 participants $(75.8 \%$ women, $55.6 \%$ widowed), aged 65-99 years (mean 79.2 \pm 7.3 years) and with low education level (63.9\%). The mean TFI total was 6.0 (SD 3.4), and frailty components with the highest prevalence were "feeling nervous or anxious" (69.0\%), "feeling down" (64.3\%) and "miss having people around" (59.9\%). Detailed information is presented in Table 1. 
Table 1 Participantcharacteristics

\begin{tabular}{|c|c|c|c|}
\hline Characteristic & $n(\%)$ & Characteristic & $n(\%)$ \\
\hline Sociodemographic characteristics & & COP sway (eyes closed) $)^{\ddagger}$ & \\
\hline Mean age (years) & $79.2 \pm 7.3$ & Mean $\mathrm{COP}_{\mathrm{x}}$ maximum velocity $(\mathrm{cm} / \mathrm{s})$ & $3.1 \pm 2.0$ \\
\hline $65-74$ & $68(27.0)$ & Mean $\mathrm{COP}_{Y}$ maximum velocity $(\mathrm{cm} / \mathrm{s})$ & $4.0 \pm 2.5$ \\
\hline $75-84$ & $116(46.0)$ & Mean $\mathrm{COP}_{x}$ maximum range $(\mathrm{cm})$ & $2.0 \pm 1.1$ \\
\hline$\geq 85$ & $68(27.0)$ & Mean $\mathrm{COP}_{Y}$ maximum range $(\mathrm{cm})$ & $2.3 \pm 0.9$ \\
\hline Sex (women) & $191(75.8)$ & Mean MMSE (0-30) & $23.6 \pm 4.9$ \\
\hline Marital status & & Cognitive deficit & $132(52.4)$ \\
\hline Married/living with partner & $49(19.4)$ & Mean GDS (0-15) & $5.4 \pm 3.9$ \\
\hline Unmarried & $24(9.5)$ & Depression & $113(44.8)$ \\
\hline Separated/divorced & $39(15.5)$ & Mean GAI (0-20) & $9.5 \pm 6.3$ \\
\hline Widow/widower & $140(55.6)$ & Severe anxiety symptoms & $130(51.6)$ \\
\hline Mean education (years) & $4.4 \pm 3.6$ & Mean SSSS(15-75) & $53.0 \pm 11.2$ \\
\hline 0 & $36(14.3)$ & Mean GFI (0-12) & $4.6 \pm 2.7$ \\
\hline $1-4$ & $161(63.9)$ & Frailty & $132(52.4)$ \\
\hline$\geq 5$ & $55(21.9)$ & Frailty phenotype components & \\
\hline Monthly household income (EUR) & & Weight loss & $40(15.9)$ \\
\hline$\leq 500$ & $103(40.9)$ & Low physical activity & $109(43.3)$ \\
\hline$\geq 501$ & $149(59.1)$ & Exhaustion & $130(51.6)$ \\
\hline Frailty assessed with TFI & & Slowed performance & $58(23.0)$ \\
\hline Mean TFI total score $(0-15)$ & $6.0 \pm 3.4$ & Weakness & $161(63.9)$ \\
\hline Mean TFI physical domain score (0-8) & $2.9 \pm 2.2$ & Mean frailty phenotype & $2.0 \pm 1.4$ \\
\hline TFI Q11: Poor physical health & $98(38.9)$ & 0 (non-frail/robust) & $39(15.5)$ \\
\hline TFI Q12: Unintentional weight loss & $40(15.9)$ & 1-2 (prefrail) & $121(48.0)$ \\
\hline TFI Q13: Difficulty in walking & $126(50.0)$ & 3-5 (frail) & $92(36.5)$ \\
\hline TFI Q14: Difficulty in maintaining & 105 (41.7) & Adverse outcomes & \\
\hline balance & & Mean Barthel Index (0-20) & $19.0 \pm 1.5$ \\
\hline TFI Q15: Poor hearing & $69(27.4)$ & Mean Lawton and Brody Scale $(0-23)$ & $17.5 \pm 5.6$ \\
\hline TFI Q16: Poor vision & $81(32.1)$ & Healthcare utilization & \\
\hline TFI Q17: Lack in hand strength & $68(27.0)$ & Contact with general practitioner & \\
\hline TFI Q18: Physical tiredness & $141(56.0)$ & 0 & $11(4.4)$ \\
\hline Mean TFI psychological domain score $(0-4)$ & $1.7 \pm 1.1$ & $1-2$ & $115(45.6)$ \\
\hline TFI Q19: Problems with memory & $61(24.2)$ & $3-4$ & $83(32.9)$ \\
\hline TFI Q20: Feeling down & $162(64.3)$ & $5-6$ & $23(9.1)$ \\
\hline TFI Q21: Feeling nervous or anxious & $174(69.0)$ & $\geq 7$ & $20(7.9)$ \\
\hline TFI Q22: Unable to cope with problems & $36(14.3)$ & Contact with healthcare professionals & $180(71.4)$ \\
\hline Mean TFI social domain score $\quad(0-3)$ & $1.4 \pm 1.0$ & Hospitalization & $62(24.6)$ \\
\hline TFI Q23: Living alone & $131(52.0)$ & Professional personal care & $17(6.7)$ \\
\hline TFI Q24: Miss having people around & $151(59.9)$ & Nursing care & $70(27.8)$ \\
\hline TFI Q25: Not receiving enough support & $68(27.0)$ & Informal care & $48(19.0)$ \\
\hline Alternative measurements of frailty & & Other healthcare or residential & $28(11.1)$ \\
\hline Mean BMI $\left(\mathrm{kg} / \mathrm{m}^{2}\right)$ & $28.6 \pm 5.4$ & care institutions & \\
\hline <18.5 (underweight) & $1(0.4)$ & Quality of life & \\
\hline $18.5-24.9$ (normal) & $64(25.4)$ & Mean EUROHIS-QOL-8 (8-40) & $27.9 \pm 5.0$ \\
\hline 25-29.9 (overweight) & $99(39.3)$ & Mean WHOQOL-OLD (28-140) & $98.4 \pm 15.7$ \\
\hline$>30$ (obese) & $88(34.9)$ & Mean sensory abilities & $15.4 \pm 4.0$ \\
\hline Mean TUG test $(\mathrm{s})^{\dagger}$ & $15.8 \pm 8.8$ & Mean autonomy & $14.0 \pm 3.0$ \\
\hline Mean handgrip strength (kg) & $19.9 \pm 8.4$ & Mean past, present and future activities & $13.4 \pm 3.0$ \\
\hline COP sway (eyes open) ${ }^{\ddagger}$ & & Mean social participation & $14.9 \pm 2.8$ \\
\hline Mean $\mathrm{COP}_{\mathrm{x}}$ maximum velocity $(\mathrm{cm} / \mathrm{s})$ & $2.4 \pm 1.5$ & Mean death and dying & $13.0 \pm 4.3$ \\
\hline Mean $\mathrm{COP}_{Y}$ maximum velocity $(\mathrm{cm} / \mathrm{s})$ & $3.0 \pm 1.5$ & Mean intimacy & $13.2 \pm 3.9$ \\
\hline Mean $\mathrm{COP}_{\mathrm{x}}$ maximum range $(\mathrm{cm})$ & $1.8 \pm 0.9$ & Mean family/family life & $14.5 \pm 4.2$ \\
\hline Mean $\mathrm{COP}_{Y}$ maximum range $(\mathrm{cm})$ & $1.9 \pm 0.7$ & & \\
\hline
\end{tabular}

$n=252 .{ }^{\dagger}$ Two cases were missing. ${ }^{\ddagger}$ Three cases were missing. BMI, body mass index; COP, center of pressure; EUROHIS-QOL, EUROHIS Quality of Life 8-item index; GAI, Geriatric Anxiety Inventory; GDS, Geriatric Depression Scale; GFI, Groningen Frailty Indicator; MMSE, Mini-Mental State Examination; SSSS, Social Support Satisfaction Scale; TFI, Tilburg Frailty Indicator; WHOQOL-OLD, World Health Organization Quality of Life - Old Module. 
Table 2 Simple agreement and Cohen's kappa coefficients of Tilburg Frailty Indicator items

\begin{tabular}{lll}
\hline TFI items & Agreement & Kappa (95\% CI) \\
\hline $\begin{array}{l}\text { Physical domain } \\
\quad \text { Physical health }\end{array}$ & 0.81 & $0.61(0.43-0.79)$ \\
$\quad$ Nutrition & 0.95 & $0.69(0.39-0.99)$ \\
Mobility & 0.85 & $0.70(0.54-0.86)$ \\
Balance & 0.87 & $0.72(0.56-0.88)$ \\
Hearing & 0.91 & $0.76(0.60-0.93)$ \\
Vision & 0.88 & $0.71(0.52-0.89)$ \\
Strength & 0.83 & $0.57(0.36-0.78)$ \\
$\quad$ Endurance & 0.81 & $0.62(0.44-0.80)$ \\
Psychological domain & & \\
$\quad$ Cognition & 0.84 & $0.52(0.28-0.77)$ \\
$\quad$ Mood & 0.78 & $0.54(0.34-0.74)$ \\
Anxiety & 0.78 & $0.53(0.33-0.74)$ \\
Coping & 0.93 & $0.76(0.56-0.96)$ \\
Social domain & & \\
$\quad$ Living alone & 0.97 & $0.95(0.87-1.00)$ \\
Social relations & 0.84 & $0.66(0.49-0.84)$ \\
$\quad$ Social support & 0.88 & $0.73(0.56-0.89)$ \\
\hline
\end{tabular}

TFI, Tilburg Frailty Indicator.

\section{Feasibility}

The researchers' training process was easy, and the administration of TFI was remarkably quick and simple. Completing TFI took on average $10 \mathrm{~min}$ (SD 4.1). All part $B$ items were easily understood by the elderly individuals. In regard to part $A$, some participants with a lower educational level required a brief explanation about the description of a healthy lifestyle (including among other aspects, eating a prudent diet, exercising frequently and not drinking excessively or smoking).

\section{Reliability}

The KR-20 was 0.78 for frailty, and $0.75,0.48,0.49$ for physical, psychological and social domains, respectively. The test-retest reliability was 0.91 (95\% CI $0.86-0.94)$ for TFI total, 0.87 (95\% CI 0.80-0.91) for physical, 0.75 (95\% CI $0.62-0.83)$ for psychological and 0.87 (95\% CI $0.80-0.91$ ) for social domains. Simple agreement was observed for all items (78-97\%), and regarding kappa coefficients, values ranged from 0.52 to 0.95 (Table 2). No statistically significant differences were found, between the total and the subsample for retest, in regard to sociodemographic characteristics and components of frailty.

\section{Construct validity}

The TFI physical domain score showed the highest correlations with BMI, TUG test, handgrip strength and most parameters regarding COP sway, whereas TFI social domain score correlated better with SSSS. In contrast, similar correlations were obtained between GDS and TFI physical and psychological domains, whereas MMSE and GAI showed the highest correlations with TFI physical domain, although not very different from the correlations obtained with the psychological domain (Table 3).

\section{Criterion validity}

To examine the criterion validity of TFI total, the area under the curve (AUC) with $95 \%$ CI for adverse outcome and alternative frailty measures was calculated, as well as the sensitivity and specificity for one or two cut-off points that gave the best results. The AUC obtained by using the GFI and the frailty phenotype as criteria was 0.89 and 0.75 , respectively. In regard to the adverse outcomes, the AUC ranged from 0.56 to 0.72 (Table 4). In the absence of an optimal cut-off point, 6 was chosen, because it showed better sensitivity and specificity.

TFI domains predicted $38.7 \%$ of quality of life variance, measured by EUROHIS-QOL- 8 and $42.1 \%$ by WHOQOL-OLD. Although each domain contributed to the prediction of quality of life, TFI physical had the largest contribution $\left(R^{2}=13.7 \%\right.$ EUROHIS-QOL-8, $R^{2}=11.6 \%$ WHOQOL-OLD). After controlling for the effect of the other two TFI domains, each one had higher correlations than the others in regard to at least two WHOQOL-OLD facets: the TFI physical domain unique contribution was stronger for "sensory abilities", "social participation" and "death and dying"; psychological domain for "autonomy" and "past, present and future activities"; whereas social domain's contribution was higher for "intimacy" and "family/family life" (Table 5).

\section{Discussion}

The present study developed a culturally adapted version of the TFI, which showed good reliability and validity when applied to a Portuguese communitydwelling sample. This sample's sociodemographic characteristics approximately resemble those of the elderly population in Portugal, in which there is an increasingly larger proportion of women, low education levels and widows in older groups. ${ }^{59}$

Internal consistency was good for frailty and for the physical domain, but rather low for psychological and social domains. These results approximately resemble the values obtained in the original and Brazilian studies. ${ }^{29,32}$ The low values can be explained by the reduced number of items in the psychological and social domains (four and three, respectively). Gobbens et al. 
Table 3 Spearman correlations between Tilburg Frailty Indicator domains and alternative frailty measurements

\begin{tabular}{|c|c|c|c|}
\hline Alternative measurements of frailty & $\begin{array}{l}\text { TFI physical } \\
\text { domain }\end{array}$ & $\begin{array}{l}\text { TFI psychological } \\
\text { domain }\end{array}$ & $\begin{array}{l}\text { TFI social } \\
\text { domain }\end{array}$ \\
\hline \multicolumn{4}{|l|}{ Physical domain } \\
\hline BMI & $0.16^{*}$ & 0.07 & 0.00 \\
\hline TUG test & $0.48^{* * *}$ & $0.21^{* * *}$ & 0.12 \\
\hline Hand grip strength & $-0.34^{* * *}$ & $-0.28^{* * *}$ & $-0.19^{* *}$ \\
\hline \multicolumn{4}{|l|}{ COP sway (eyes open) } \\
\hline $\mathrm{COP}_{\mathrm{x}}$ maximum velocity & $0.17^{* *}$ & 0.02 & 0.03 \\
\hline $\mathrm{COP}_{Y}$ maximum velocity & $0.13^{*}$ & -0.06 & -0.08 \\
\hline $\mathrm{COP}_{x}$ maximum range & $0.17^{* *}$ & 0.03 & 0.08 \\
\hline $\mathrm{COP}_{Y}$ maximumrange & $0.15^{*}$ & 0.00 & -0.07 \\
\hline \multicolumn{4}{|l|}{ COP sway (eyes closed) } \\
\hline $\mathrm{COP}_{x}$ maximum velocity & 0.09 & -0.02 & 0.01 \\
\hline $\mathrm{COP}_{Y}$ maximum velocity & 0.07 & 0.01 & -0.02 \\
\hline $\mathrm{COP}_{x}$ maximum range & $0.18^{* *}$ & 0.06 & 0.04 \\
\hline $\mathrm{COP}_{Y}$ maximum range & 0.07 & 0.10 & 0.02 \\
\hline \multicolumn{4}{|l|}{ Psychological domain } \\
\hline MMSE & $-0.26^{* * *}$ & $-0.22^{* * *}$ & -0.06 \\
\hline GDS & $0.58^{* * *}$ & $0.58^{* * *}$ & $0.41^{* * *}$ \\
\hline GAI & $0.58^{* * *}$ & $0.56^{* * *}$ & $0.29 * * *$ \\
\hline \multicolumn{4}{|l|}{ Social domain } \\
\hline SSSS & $-0.35^{* * *}$ & $-0.37^{* * *}$ & $-0.43^{* * *}$ \\
\hline
\end{tabular}

${ }^{*} P<0.05$. ${ }^{* *} P<0.01$. ${ }^{* * *} P<0.001$. Highest significant correlation of each row printed in bold. BMI, body mass index; COP, center of pressure; GAI, Geriatric Anxiety Inventory; GDS, Geriatric Depression Scale; MMSE, Mini-Mental State Examination; SSSS, Social Support Satisfaction Scale; TFI, Tilburg Frailty Indicator.

Table 4 Receiver operating characteristic analysis of Tilburg Frailty Indicator total score in regard to criteria of frailty and adverse outcomes

\begin{tabular}{|c|c|c|c|c|}
\hline Measure/criterion & TFI cut-point & Sensitivity & Specificity & AUC (95\% CI) \\
\hline \multicolumn{5}{|l|}{ Alternative frailty measures } \\
\hline \multirow[t]{2}{*}{ GFI } & $\geq 5$ & 0.84 & 0.78 & $0.89(0.85-0.93)$ \\
\hline & $\geq 6$ & 0.74 & 0.86 & \\
\hline \multirow[t]{2}{*}{ Frailty phenotype } & $\geq 5$ & 0.78 & 0.59 & $0.75(0.68-0.81)$ \\
\hline & $\geq 6$ & 0.71 & 0.69 & \\
\hline \multicolumn{5}{|l|}{ Disability } \\
\hline \multirow[t]{2}{*}{ Barthel Index } & $\geq 5$ & 0.70 & 0.60 & $0.72(0.66-0.78)$ \\
\hline & $\geq 6$ & 0.64 & 0.73 & \\
\hline \multirow[t]{2}{*}{ Lawton and Brody Scale } & $\geq 4$ & 0.65 & 0.56 & $0.63(0.53-0.72)$ \\
\hline & $\geq 5$ & 0.58 & 0.58 & \\
\hline \multicolumn{5}{|l|}{ Healthcare utilization } \\
\hline \multirow[t]{2}{*}{ Contact with general practitioner } & $\geq 6$ & 0.63 & 0.58 & $0.64(0.56-0.73)$ \\
\hline & $\geq 7$ & 0.54 & 0.67 & \\
\hline Contact with healthcare professionals & $\geq 5$ & 0.58 & 0.54 & $0.57(0.49-0.65)$ \\
\hline Hospitalization & $\geq 6$ & 0.57 & 0.58 & $0.60(0.51-0.68)$ \\
\hline \multirow[t]{2}{*}{ Professional personal care } & $\geq 6$ & 0.65 & 0.56 & $0.63(0.49-0.77)$ \\
\hline & $\geq 7$ & 0.59 & 0.64 & \\
\hline Nursing care & $\geq 6$ & 0.51 & 0.57 & $0.56(0.49-0.64)$ \\
\hline Informal care & $\geq 6$ & 0.58 & 0.58 & $0.60(0.52-0.68)$ \\
\hline \multirow[t]{2}{*}{ Other healthcare or residential care institutions } & $\geq 6$ & 0.57 & 0.56 & $0.59(0.48-0.69)$ \\
\hline & $\geq 7$ & 0.50 & 0.64 & \\
\hline
\end{tabular}

Optimal cut-points of each criterion printed in bold. GFI, Groningen Frailty Indicator; TFI, Tilburg Frailty Indicator. 


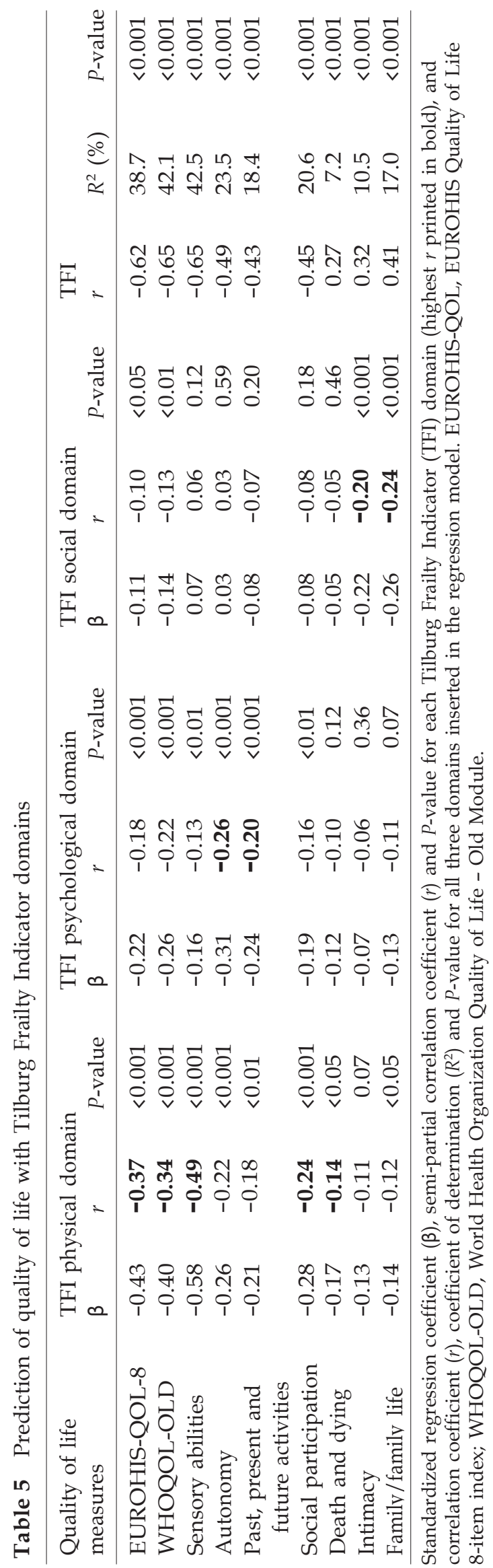

recognized this, but preferred to value the benefits of assessing these domains with the fewest possible questions. ${ }^{29}$

Regarding kappa coefficients, it was observed that four items showed moderate agreement (0.41-0.60), 10 showed substantial agreement $(0.61-0.80)$ and one showed nearly perfect agreement $(0.81-1.00)$ according to the Landis and Koch classification..$^{60}$ The TFI total and each domain score obtained in both assessments were also found to be highly correlated. In accordance with other TFI validation studies, these results showed a good test-retest reliability. ${ }^{29,32}$

TFI also showed good construct validity (convergent/divergent) in regard to its physical and social domains, as each correlated as expected with alternative physical and social measures. The same cannot be said regarding TFI psychological domain's divergent validity, as other psychological measures correlated equally or slightly better with the physical domain than with the psychological one. Gobbens et al. $^{29}$ had already drawn similar results regarding MMSE, whereas Santiago et al. ${ }^{32}$ also struggled to find alternative psychological measures that correlated better with the TFI psychological domain. These results can be explained by the well-documented relationship between cognitive and physical performance, ${ }^{61}$ and between depression ${ }^{62}$ and anxiety ${ }^{63}$ and selfreported physical function.

ROC analysis used to assess TFI criterion validity showed that its discrimination ability was excellent regarding the identification of those classified as frail by GFI, and good for frailty detected by the frailty phenotype. The prediction of disability in ADL was good and fair for the remaining adverse outcomes (dependence on instrumental ADL and healthcare utilization). Choosing 6 as a cut-off for frailty, $54.8 \%$ of the participants were identified as frail. This prevalence is remarkably similar to the proportion of frail participants identified in our sample by GFI $(52.4 \%)$, larger than the prevalence of frailty detected by this operationalization of its phenotype $(36.5 \%)$, and higher than observed in other studies that used the TFI in a community setting. Values from $31.7 \%{ }^{32}$ to $47.1 \%^{29}$ have been reported. One possible explanation for the substantial difference observed between the Brazilian study ${ }^{32}$ and this research could be the age of participants (significantly younger in the first one).

The good criterion validity of the TFI was also supported by its ability to predict quality of life. Besides assuming a primary role in predicting EUROHIS- QOL8 and WHOQOL-OLD totals, the TFI physicaldomain also had the highest correlation of the three domains with the largest number of WHOQOL-OLD facets. The highest contribution of the physical domain for the explanation of quality of life emphasizes its importance in the conceptualization of frailty, but the 
value added by the other domains provides robust evidence for an integral definition of the syndrome.

The rigorous process of translation and cultural adaptation, and thorough study of several psychometric properties were the main strengths of this research. Nevertheless, some limitations should be highlighted. First, test-retest reliability reported only on a second application of TFI 2 weeks after the first inquiry, and that difference could provide different results. Second, the correlations between each TFI item and correspondent other validated measures were not examined, which could provide additional evidence about construct validity. The cross-sectional nature of the present study can also be considered as a limitation, as it does not allow understanding of the temporal continuum between frailty and adverse outcomes. Finally, the nonprobability sampling method could have limited these findings regarding the generalization of results. Nevertheless, considering that the psychometric properties of this version resemble those obtained in other validation studies, these results are promising.

Longitudinal studies should be carried out to better examine how frailty, and each domain, predicts adverse outcomes in the short, medium and long term. Likewise, understanding which variables/determinants (e.g. sociodemographic characteristics, life events, lifestyle) can effectively predict frailty in general, and each domain in particular, is essential to implement timely and targeted interventions in order to prevent the syndrome and its adverse outcomes. Although benefits can be drawn by measuring frailty with the multidimensional TFI, further research should be carried out to better understand which frailty definition and operationalization concept should be chosen. Also, further research about the TFI cut-off for frailty and its application in other contexts (e.g. hospital, primary care, nursing home) should be carried out.

In conclusion, this research provides robust evidence that this TFI version is a valid and reliable measure for assessing frailty in Portuguese older adults. Consequently, it provided a simple, but invaluable, tool for health/social care providers and for researchers that effectively identifies highly vulnerable older persons in a multidimensional perspective, allowing more focused and efficient interventions to prevent adverse outcomes.

\section{Acknowledgments}

The authors thank all the elderly participants, and all professionals who assisted and made the data collection possible, particularly occupational therapy students (Alice Rocha, Joana Oliveira, Libânia Silva, Nicole Câmara, Rute Ferreira, Sara Santos, Stefanie Morais and Sylvie Abreu) for partial data collecting. The authors thank Carolina Silva, Ignácio Martin and Mafalda Duarte for being part of the expert committee, as well as
Maria Vilar and Mário Simões for allowing the use of the WHOQOL-OLD experimental Portuguese version; also Carolina Silva for assistance with the statistical analysis and Peter Blackburn for the back-translation procedure.

\section{Disclosure statement}

No potential conflicts of interest were disclosed.

\section{References}

1 Proportion of population aged 65 and over [Internet]. 2014 [Cited 23 Jan 2014.] Available from URL: http:// epp.eurostat.ec.europa.eu/tgm/table.do?tab=table\&init=1 \&plugin $=1 \&$ language $=$ en\&pcode $=$ tps 00028 .

2 Bergman H, Ferrucci L, Guralnik J et al. Frailty: an emerging research and clinical paradigm-issues and controversies. J Gerontol A Biol Sci Med Sci 2007; 62: 731-737.

3 Fried LP, Tangen CM, Walston J et al. Frailty in older adults: evidence for a phenotype. J Gerontol A Biol Sci Med Sci 2001; 56 (3): M146-M156.

4 Hogan DB, MacKnight C, Bergman H. Models, definitions, and criteria of frailty. Aging Clin Exp Res 2003; 15 (3 Suppl): 1-29.

5 Gobbens RJ, Luijkx KG, Wijnen-Sponselee MT, Schols JM. Towards an integral conceptual model of frailty. J Nutr Health Aging 2010; 14: 175-181.

6 Markle-Reid M, Browne G. Conceptualizations of frailty in relation to older adults. J Adv Nurs 2003; 44: 58-68.

7 Abellan van Kan G, Rolland Y, Bergman H, Morley JE, Kritchevsky SB, Vellas B. The I.A.N.A Task Force on frailty assessment of older people in clinical practice. JNutr Health Aging 2008; 12 (1): 29-37.

8 Rockwood K, Mitnitski A. Frailty in relation to the accumulation of deficits. J Gerontol A Biol Sci Med Sci 2007; 62: 722-727.

9 Fried LP, Ferrucci L, Darer J, Williamson JD, Anderson G. Untangling the concepts of disability, frailty, and comorbidity: implications for improved targeting and care. J Gerontol A Biol Sci Med Sci 2004; 59: 255-263.

10 Rockwood K, Song X, MacKnight C et al. A global clinical measure of fitness and frailty in elderly people. CMAJ 2005; 173: 489-495.

11 Puts MT, Lips P, Deeg DJ. Static and dynamic measures of frailty predicted decline in performance-based and selfreported physical functioning. J Clin Epidemiol 2005; 58: 1188-1198.

12 Zaslavsky O, Cochrane BB, Thompson HJ, Woods NF, Herting JR, LaCroix A. Frailty: a review of the first decade of research. Biol Res Nurs 2013; 15: 422-432.

13 Fried LP, Walston J, Ferrucci L. Frailty. In: Halter JB, Ouslander JG, Tinetti ME, Studenski S, High KP, Asthana S, eds. Hazzard's Geriatric Medicine and Gerontology, 6th edn. New York: McGraw-Hill, 2009; 631-646.

14 Avila-Funes JA, Helmer C, Amieva H et al. Frailty among community-dwelling elderly people in France: the threecity study. J Gerontol A Biol Sci Med Sci 2008; 63: 1089-1096.

15 Sternberg SA, Wershof Schwartz A, Karunananthan S, Bergman H, Mark Clarfield A. The identification of frailty: a systematic literature review. J Am Geriatr Soc 2011; 59: 2129-2138.

16 Bergman H, Béland F, Karunananthan S, Hummel S, Hogan D, Wolfson C. English translation of article 
published in "Gerontologie et société". Dévelopment d'un cadre de travail pour compendre et étudier la fragilité. Gerontol Soc 2004; 109: 15-29.

17 Walston J, Hadley EC, Ferrucci L et al. Research agenda for frailty in older adults: toward a better understanding of physiology and etiology: summary from the American Geriatrics Society/National Institute on Aging Research Conference on Frailty in Older Adults. J Am Geriatr Soc 2006; 54: 991-1001.

18 Gobbens RJ, Luijkx KG, Wijnen-Sponselee MT, Schols JM. Toward a conceptual definition of frail community dwelling older people. Nurs Outlook 2010; 58: 76-86.

19 Bortz WM, 2nd. A conceptual framework of frailty: a review. J Gerontol A Biol Sci Med Sci 2002; 57 (5): M283M288.

20 Campbell AJ, Buchner DM. Unstable disability and the fluctuations of frailty. Age Ageing 1997; 26: 315-318.

21 Ahmed N, Mandel R, Fain MJ. Frailty: an emerging geriatric syndrome. Am J Med 2007; 120: 748-753.

22 Rothman MD, Leo-Summers L, Gill TM. Prognostic significance of potential frailty criteria. J Am Geriatr Soc 2008; 56: 2211-2216

23 Levers MJ, Estabrooks CA, Ross Kerr JC. Factors contributing to frailty: literature review. J Adv Nurs 2006; 56: $282-$ 291.

24 Ravaglia G, Forti P, Lucicesare A, Pisacane N, Rietti E, Patterson C. Development of an easy prognostic score for frailty outcomes in the aged. Age Ageing 2008; 37: 161-166.

25 Rolfson DB, Majumdar SR, Tsuyuki RT, Tahir A, Rockwood K. Validity and reliability of the Edmonton Frail Scale. Age Ageing 2006; 35: 526-529.

26 Gobbens RJ, Luijkx KG, Wijnen-Sponselee MT, Schols JM. In search of an integral conceptual definition of frailty: opinions of experts. J Am Med Dir Assoc 2010; 11: 338343.

27 Sourial N, Wolfson C, Bergman H et al. A correspondence analysis revealed frailty deficits aggregate and are multidimensional. J Clin Epidemiol 2010; 63: 647-654.

28 Gobbens RJ, van Assen MA, Luijkx KG, Schols JM. Testing an integral conceptual model of frailty. J Adv Nurs 2012; 68: 2047-2060.

29 Gobbens RJ, van Assen MA, Luijkx KG, Wijnen-Sponselee MT, Schols JM. The Tilburg Frailty Indicator: psychometric properties. J Am Med Dir Assoc 2010; 11: 344-355.

30 Gobbens RJ, van Assen MA. Frailty and its prediction of disability and health care utilization: the added value of interviews and physical measures following a self-report questionnaire. Arch Gerontol Geriatr 2012; 55: 369-379.

31 Podsiadlo D, Richardson S. The timed "Up \& Go": a test of basic functional mobility for frail elderly persons. J Am Geriatr Soc 1991; 39: 142-148.

32 Santiago LM, Luz LL, Mattos IE, Gobbens RJ, van Assen MA. Psychometric properties of the Brazilian version of the Tilburg frailty indicator (TFI). Arch Gerontol Geriatr 2013; 57: $39-45$.

33 Santiago LM, Luz LL, Mattos IE, Gobbens RJ. Crosscultural adaptation of the Tilburg Frailty Indicator (TFI) for use in the Brazilian population. Cad Saúde Pública 2012; 28: $1795-1801$.

34 Andreasen J, Sørensen EE, Gobbens RJJ, Lund H, Aadahl M. Danish version of the Tilburg Frailty Indicator - Translation, Cross-cultural Adaption and Validity Pretest by Cognitive Interviewing. Arch Gerontol Geriatr 2014; 59: 3238.

35 Pialoux T, Goyard J, Lesourd B. Screening tools for frailty in primary health care: a systematic review. Geriatr Gerontol Int 2012; 12: 189-197.
36 Metzelthin SF, Daniels R, van Rossum E, de Witte L, van den Heuvel WJ, Kempen GI. The psychometric properties of three self-report screening instruments for identifying frail older people in the community. BMC Public Health 2010; 10: 176

37 Wild D, Grove A, Martin M et al. Principles of Good Practice for the Translation and Cultural Adaptation Process for Patient-Reported Outcomes (PRO) Measures: report of the ISPOR Task Force for Translation and Cultural Adaptation. Value Health 2005; 8: 94-104.

38 Folstein MF, Folstein SE, McHugh PR. "Mini-mental state". A practical method for grading the cognitive state of patients for the clinician. J Psychiatr Res 1975; 12: 189-198.

39 Morgado J, Rocha CS, Maruta C, Guerreiro M, Martins IP. New normative values of mini-mental state examination. Sinapse 2009; 9 (2): 19-25.

40 Sheikh JI, Yesavage JA. Geriatric Depression Scale (GDS). Recent evidence and development of a shorter version. Clin Gerontol 1986; 5 (1-2): 165-173.

41 Pachana NA, Byrne GJ, Siddle H, Koloski N, Harley E, Arnold E. Development and validation of the Geriatric Anxiety Inventory. Int Psychogeriatr 2007; 19: 103-114.

42 Ribeiro O, Paul C, Simoes MR, Firmino H. Portuguese version of the Geriatric Anxiety Inventory: transcultural adaptation and psychometric validation. Aging Ment Health 2011; 15: 742-748.

43 Pais-Ribeiro JL. Escala de Satisfação com o Suporte Social (ESSS). Anál Psicol 1999; 3 (XVII): 547-558.

44 Schuurmans H, Steverink N, Lindenberg S, Frieswijk N, Slaets JP. Old or frail: what tells us more? J Gerontol A Biol Sci Med Sci 2004; 59 (9): M962-M965.

45 Duarte M. Fragilidade nas pessoas idosas [Frailty in Elderly People]. Porto: Institute of Biomedical Sciences Abel Salazar of University of Porto, 2013.

46 Mahoney FI, Barthel DW. Functional evaluation: the Barthel Index. Md State Med J 1965; 14: 61-65.

47 Araújo F, Ribeiro JLP, Oliveira A, Pinto C. Validação do Índice de Barthel numa amostra de idosos não institucionalizados. Rev Port Saúde Pública 2007; 25 (2): 59-66.

48 Araújo F, Pais Ribeiro J, Oliveira A, Pinto C, Martins T. Validação da escala de Lawton e Brody numa amostra de idosos não institucionalizados [Lawton and Brody scale validation in a sample of non-institutionalized elderly]. In: Leal I, Pais-Ribeiro J, Silva I, Marques S, eds. Actas do $7^{\circ}$ congresso nacional de psicologia da saúde. Lisboa: ISPA, 2008; 217-220.

49 Lawton MP, Brody EM. Assessment of older people: selfmaintaining and instrumental activities of daily living. Gerontologist 1969; 9: 179-186.

50 Pereira M, Melo C, Gameiro S, Canavarro MC. Estudos psicométricos da versão em Português Europeu do índice de qualidade de vida EUROHIS-QOL-8. Lab Psicol 2011; 9: 109-123.

51 Schmidt S, Muhlan H, Power M. The EUROHIS-QOL 8item index: psychometric results of a cross-cultural field study. Eur J Public Health 2006; 16: 420-428.

52 Vilar M, Simões MR, Sousa LB, Firmino H, Paredes T, Lima MP. Avaliação da Qualidade de Vida em Adultos Idosos: Notas em torno do processo de adaptação e validação do WHOQOL-OLD para a população portuguesa [Quality of life assessment in older adults. Notes of the adaptation and validation process of WHOQOL-OLD for the Portuguese population]. In: Canavarro MC, Serra AV, eds. qualidade de vida e saúde: Uma abordagem na perspectiva da Organização Mundial De Saúde. Lisboa: F. C. Gulbenkian, 2010; 229-250. 
53 Power M, Quinn K, Schmidt S, Group W-O. Development of the WHOQOL-old module. Qual Life Res 2005; 14: 2197-2214.

54 Roberts HC, Denison HJ, Martin HJ et al. A review of the measurement of grip strength in clinical and epidemiological studies: towards a standardised approach. Age Ageing 2011; 40: 423-429.

55 Palmieri RM, Ingersoll CD, Stone MB, Krause BA. Centerof-pressure parameters used in the assessment of postural control. J Sport Rehabil 2002; 11: 51-66.

56 Santos-Eggimann B, Cuenoud P, Spagnoli J, Junod J. Prevalence of frailty in middle-aged and older communitydwelling Europeans living in 10 countries. J Gerontol A Biol Sci Med Sci 2009; 64: 675-681.

57 Gobbens RJ, van Assen MA, Luijkx KG, Schols JM. The predictive validity of the Tilburg frailty indicator: disability, health care utilization, and quality of life in a population at risk. Gerontologist 2012; 52: 619-631.

58 Gobbens RJ, Luijkx KG, van Assen MA. Explaining quality of life of older people in the Netherlands using a multidimensional assessment of frailty. Qual Life Res 2012; 22: 2051-2061.

59 INE. Censos 2011 Resultados Definitivos - Portugal [2011 Census Final Results - Portugal]. Lisboa: Instituto Nacional de Estatística (INE), I. P., 2012.
60 Landis JR, Koch GG. The measurement of observer agreement for categorical data. Biometrics 1977; 33: 159-174.

61 Fitzpatrick AL, Buchanan CK, Nahin RL et al. Associations of gait speed and other measures of physical function with cognition in a healthy cohort of elderly persons. J Gerontol A Biol Sci Med Sci 2007; 62: 1244-1251.

62 Stegenga BT, Nazareth I, Torres-Gonzalez F et al. Depression, anxiety and physical function: exploring the strength of causality. J Epidemiol Community Health 2012; 66 (7): e25.

63 Mehta KM, Yaffe K, Brenes GA et al. Anxiety symptoms and decline in physical function over 5 years in the health, aging and body composition study. J Am Geriatr Soc 2007; 55: $265-270$.

\section{Supporting Information}

Additional Supporting Information may be found in the online version of this article at the publisher's web-site:

Description of the additional measures. English and Portuguese versions of the Tilburg Frailty Indicator. 